\title{
Endoscopic radiofrequency ablation therapy for the prevention of esophageal cancer in Barrett's esophagus
}

This article was published in the following Dove Press journal:

Gastrointestinal Cancer: Targets and Therapy

29 July 2015

Number of times this article has been viewed

\section{Ngoc Hoang $\mathrm{Ha}$ \\ Richard Hummel \\ David I Watson}

Department of Surgery, Flinders University, Flinders Medical Centre, Bedford Park, Adelaide, South Australia, Australia
Correspondence: David I Watson Department of Surgery, Flinders University, Room 3D2II, Flinders Medical Centre, Bedford Park, Adelaide, South Australia 5042, Australia

Tel +6I 882046086

Fax +61 882046130

Email david.watson@flinders.edu.au
Abstract: Barrett's esophagus is the only known precursor lesion for esophageal adenocarcinoma. Previous studies have shown that a variety of methods can be applied to destroy Barrett's esophagus epithelium, and healing with a new esophageal squamous epithelium usually occurs following ablation. Radiofrequency ablation (RFA) is a relatively new endoscopic technique. It has been claimed that ablation using RFA reduces the risk of cancer progression. RFA is usually easy to apply and is associated with a low risk of morbidity. It achieves complete eradication of (non) dysplastic Barrett's esophagus in most individuals, and the risk of progression to higher grades of dysplasia or cancer is reduced after RFA, although not completely eliminated. Limitations include recurrence of Barrett's esophagus in up to one-third of individuals, a risk of "buried islands" of Barrett's esophagus remaining below the regenerated mucosa, and uncertainty about the biological behavior of the new squamous epithelium after RFA. Current evidence supports the use of RFA in individuals with high-grade dysplasia in Barrett's esophagus, and early stage (T1a) intramucosal cancer, and select individuals with low-grade dysplasia. As accurate diagnosis of low-grade dysplasia remains difficult outside expert centers, it is probably premature to recommend routine RFA for all patients diagnosed with low-grade dysplasia in the community, despite the favorable outcomes from one randomized trial. Furthermore, long-term outcomes following ablation remain uncertain, and ongoing endoscopy surveillance is still required after RFA as progression to cancer remains a possibility. Outcomes from large studies with long-term follow-up are needed to definitively confirm that RFA ablation can reliably prevent cancer progression in Barrett's esophagus.

Keywords: Barrett's esophagus, esophageal adenocarcinoma, radiofrequency ablation, dysplasia

\section{Introduction Background}

The incidence of esophageal adenocarcinoma in Western countries has risen significantly over recent decades, with the rate of increase more rapid than for any other cancer. ${ }^{1-4}$ Barrett's esophagus is the only known premalignant precursor, and it represents a major risk factor for esophageal adenocarcinoma. It is thought to be an adaptive response to gastroesophageal reflux-associated mucosal injury, which leads to the normal stratified squamous epithelium in the distal esophagus undergoing metaplastic change to a columnar epithelium. In most parts of the world, Barrett's esophagus is not diagnosed unless intestinal metaplasia is identified at histopathology. However, in reality, the metaplastic columnar epithelium often contains a mosaic of intestinal metaplasia, and fundic and cardia mucosa. 
Progression of Barrett's esophagus to cancer is thought to occur in a stepwise manner, with the metaplastic columnar epithelium undergoing dysplastic change, from low-grade dysplasia (LGD) to high-grade dysplasia (HGD), which can then progress to adenocarcinoma. ${ }^{5}$ Metaplastic Barrett's esophagus is associated with a low overall risk of progression to esophageal adenocarcinoma of $0.12 \%-0.40 \%$ per year. ${ }^{6-10}$ It is important to note that most individuals with Barrett's esophagus will never actually develop esophageal adenocarcinoma. In addition, most patients who do develop esophageal adenocarcinoma have no prior history of Barrett's esophagus. This latter observation might be somewhat "biased", however, as these patients may well have had undiscovered Barrett's esophagus, as they had not undergone earlier endoscopy. The risk of Barrett's esophagus progressing to cancer greatly increases once HGD develops, with up to $40 \%-60 \%$ of individuals with HGD progressing to cancer across a $3-5$ year time frame. ${ }^{11,12}$

Overall, the incidence of Barrett's esophagus in the general population is probably low, ranging from $1 \%$ to $2 \%$, with the lowest prevalence $(<1 \%)$ seen in Asian countries. ${ }^{13}$ However, this figure ranges from $10 \%$ to $15 \%$ in individuals who undergo endoscopy for symptoms of gastroesophageal reflux. ${ }^{14}$ Other major risk factors for Barrett's esophagus include age, male sex, abdominal obesity, smoking, family history, and Caucasian racial background. ${ }^{15-21}$

\section{Current management of Barrett's esophagus}

Current management of known Barrett's esophagus in most Western countries usually entails regular endoscopy surveillance to identify cancer at its earliest stage followed by medication or antireflux surgery to control symptoms of gastroesophageal reflux disease. ${ }^{22-26}$ More recently, however, new endoscopic treatment options have been advocated for individuals with dysplastic Barrett's esophagus, with these treatments aiming to reverse the dysplasia or treat early (intramucosal) cancer.

Traditionally, endoscopy surveillance has been used to detect dysplasia and early cancer, thereby providing opportunities for early intervention. Given the relatively low overall risk of progression $(0.12 \%-0.40 \%$ per year), there has been debate about the cost-effectiveness of endoscopy-based surveillance strategies, with health economic evaluations failing to demonstrate clear advantages for endoscopy surveillance programs. ${ }^{26,27}$ This has led to more recent endoscopy surveillance guidelines from Australia and the UK, recommending less frequent surveillance in lower risk individuals with shorter, nondysplastic segments of Barrett's esophagus. ${ }^{23,24}$ Recently published Australian guidelines, for example, recommend that the timing of repeat endoscopy in patients with Barrett's esophagus who do not have dysplasia should be based on the Barrett's esophagus segment length. If the length is less than $3 \mathrm{~cm}$, repeat endoscopy is recommended for 3-5 years' time, whereas if the length is $3 \mathrm{~cm}$ or greater, then repeat endoscopy should be earlier, in 2-3 years' time. When the biopsies show Barrett's esophagus indefinite for dysplasia (IND), repeat endoscopy is recommended for 6 months, and for LGD, 6 monthly endoscopies are recommended until either progression, or if two consecutive endoscopies show no dysplasia, then the interval can be extended. If HGD or adenocarcinoma is found, then patients should be considered for definitive management. ${ }^{23}$

It is generally accepted that antireflux treatments should be used to minimize or eliminate symptoms of gastroesophageal reflux in individuals with Barrett's esophagus. However, there is debate about whether treatment of reflux reduces cancer risk. Proton pump inhibitors are usually the first choice for the treatment of reflux symptoms associated with Barrett's esophagus, and higher than standard doses are often required to achieve effective symptom control. ${ }^{22,28,29}$ A recent large-scale systematic review and meta-analysis which included $>2,800$ patients with Barrett's esophagus suggested that the use of proton pump inhibitors is associated with a 71\% reduction in risk of HGD and/or adenocarcinoma (adjusted OR [odds ratio], 0.29; 95\% CI [confidence interval], 0.12-0.79). However, the reliability of the conclusions from this study are limited by the lack of underlying data from randomized controlled trials, the inclusion of patients with LGD in the Barrett's esophagus population, and the considerable heterogeneity of the data sets used for meta-analysis. ${ }^{30}$ It should also be noted that despite good symptom control being achieved in most patients, regression of Barrett's esophagus is rarely seen following medical therapy alone. ${ }^{31}$

Antireflux surgery such as fundoplication is the other treatment option. ${ }^{32,33}$ Surgery alone also fails to reliably produce regression of Barrett's esophagus, or prevent progression to adenocarcinoma. ${ }^{34-38}$ While some prospective cohort studies have suggested that fundoplication might lead to regression, ${ }^{39}$ only one randomized trial has compared Nissen fundoplication vs medical therapy in Barrett's esophagus. In this trial, patients treated with surgery had a small reduction in the length of Barrett's esophagus segment (median reduction: $1 \mathrm{~cm}$ ) at 5 years, whereas those treated medically had an increase in length (median increase: $1 \mathrm{~cm}$ ). 
However, there was no difference in the rate of progression to cancer or HGD between the two groups. ${ }^{36}$

\section{Ablation of Barrett's esophagus}

As antireflux therapy alone is not effective for the eradication of Barrett's esophagus, various ablative therapies have been developed, all aiming to reverse the process of Barrett's esophagus. These treatments aim to destroy or remove the abnormal Barrett's esophagus mucosa and replace the metaplastic epithelium with a "normal" stratified squamous epithelium, thereby potentially decreasing the risk of progression to adenocarcinoma. ${ }^{40,41}$ Ablative therapies include several different techniques, all of which aim to destroy the metaplastic Barrett's esophagus mucosa (Table 1). These include argon plasma coagulation (APC), laser heater probe, photodynamic therapy (PDT), and radiofrequency ablation (RFA).$^{42}$ In addition to ablation therapy, concurrent pharmacological therapies to reduce gastric acid production, and hence reflux, are thought to be important, as they aim at generating a reflux-free environment during the mucosal healing period. ${ }^{43}$ All treatments that achieve these aims, ie, destruction of the metaplastic mucosa in an individual with well-controlled reflux, appear to be capable of generating regression of
Barrett's esophagus, although the ease of treatment and the success rate varies between different options.

APC uses monopolar electrocautery and produces a stream of ionized argon gas to deliver a high-frequency electrical current to the esophageal mucosa. This cauterizes and destroys the mucosa. The equipment required is relatively inexpensive and widely available. Randomized trials have shown that APC can effectively clear the Barrett's esophagus mucosa, at least in the short-term. ${ }^{44-48} \mathrm{~A}$ randomized control trial reported by Sie et al ${ }^{44}$ divided 129 patients with nondysplastic or LGD Barrett's esophagus into two groups: one group receiving APC, the other undergoing endoscopy surveillance. In the APC group, more than 95\%-100\% eradication of Barrett's esophagus was initially achieved in $97 \%$ of patients. At 1 year follow-up, $84 \%$ still had effective eradication of the Barrett's esophagus, although this declined to $66 \%$ at 5 years follow-up. ${ }^{45}$

An alternative ablation option is PDT. This requires the administration of a photosensitizer drug (eg, oral aminolevulinic acid or intravenous Photofrin), and the Barrett's esophagus is then exposed to laser light via an endoscope. During this process, the photosensitizer is activated by a specific wavelength of light, resulting in mucosal injury. ${ }^{49,50}$ This

Table I Competing methods for ablation of Barrett's esophagus

\begin{tabular}{|c|c|c|c|c|}
\hline Treatment & $\begin{array}{l}\text { Mechanism of } \\
\text { action }\end{array}$ & $\begin{array}{l}\text { Eradication } \\
\text { rate }\end{array}$ & Advantages & Disadvantages \\
\hline $\begin{array}{l}\text { Argon plasma } \\
\text { coagulation } \\
\text { (APC) }\end{array}$ & $\begin{array}{l}\text { lonized argon carrying } \\
\text { high-frequency } \\
\text { electrical current }\end{array}$ & $80 \%-90 \%$ & $\begin{array}{l}\text { Inexpensive } \\
\text { Equipment widely available }\end{array}$ & $\begin{array}{l}\text { Operator dependent } \\
\text { Limited long-term outcome data } \\
\text { Recurrence in some individuals }\end{array}$ \\
\hline $\begin{array}{l}\text { Photodynamic } \\
\text { therapy (PDT) }\end{array}$ & $\begin{array}{l}\text { Photosensitizing } \\
\text { agent plus laser } \\
\text { light activation via } \\
\text { endoscope }\end{array}$ & $50 \%-90 \%$ & Reproducible application technique & $\begin{array}{l}\text { Expensive } \\
\text { Equipment not widely available } \\
\text { Photosensitivity limits applicability in many } \\
\text { countries } \\
\text { Recurrence in some individuals }\end{array}$ \\
\hline $\begin{array}{l}\text { Radiofrequency } \\
\text { ablation therapy } \\
\text { (RFA) }\end{array}$ & $\begin{array}{l}\text { Bipolar electrical } \\
\text { current }\end{array}$ & $80 \%-90 \%$ & $\begin{array}{l}\text { Simple reproducible application } \\
\text { Equipment increasingly available }\end{array}$ & $\begin{array}{l}\text { Expensive consumables } \\
\text { Not suitable for nodular mucosa or } \\
\text { difficult anatomy } \\
\text { Recurrence in some individuals }\end{array}$ \\
\hline $\begin{array}{l}\text { Endoscopic } \\
\text { mucosal } \\
\text { resection (EMR) }\end{array}$ & $\begin{array}{l}\text { Endoscopic removal } \\
\text { of mucosa in } \\
\text { piecemeal fashion }\end{array}$ & $76 \%-100 \%$ & $\begin{array}{l}\text { Large tissue "biopsy" facilitates accurate } \\
\text { histology } \\
\text { Complete excision of shorter Barrett's } \\
\text { esophagus segments feasible } \\
\text { Can remove nodular lesions } \\
\text { Can be used as an adjunct to other therapies }\end{array}$ & $\begin{array}{l}\text { Excised mucosal pieces limited to } 1.5-2 \mathrm{~cm} \\
\text { diameter. Piecemeal resection required for } \\
\text { larger areas } \\
\text { Complications in some individuals - } \\
\text { bleeding, perforation, stricture }\end{array}$ \\
\hline $\begin{array}{l}\text { Endoscopic } \\
\text { submucosal } \\
\text { dissection (ESD) }\end{array}$ & $\begin{array}{l}\text { Endoscopic removal } \\
\text { of mucosa (single } \\
\text { larger piece) }\end{array}$ & $76 \%-100 \%$ & $\begin{array}{l}\text { Can remove nodular lesions } \\
\text { More extensive "en bloc" resection of } \\
\text { mucosa achievable }\end{array}$ & $\begin{array}{l}\text { Long learning curve - technically challenging } \\
\text { Higher stricture rate than following EMR } \\
\text { Other complications - bleeding, perforation } \\
\text { Procedures take a long time. } \\
\text { Costly }\end{array}$ \\
\hline Surgery & Esophagectomy & $100 \%$ & $\begin{array}{l}\text { Curative } \\
\text { No further surveillance required after } \\
\text { treatment }\end{array}$ & $\begin{array}{l}\text { Perioperative morbidity, mortality } \\
\text { Impact on quality of life }\end{array}$ \\
\hline
\end{tabular}


technique has been shown to be successful in eradicating the metaplastic epithelium in $50 \%-90 \%$ of patients. ${ }^{51,52}$ However, the required equipment is expensive and not widely available, and a major issue is that patients must remain in a darkened room for long periods of time after administration of the photosensitizer, as they are rendered severely sensitive to light, and the potential damage to their skin is very high..$^{53}$

Direct excision of the Barrett's esophagus mucosa can be achieved using endoscopic mucosal resection (EMR) or endoscopic submucosal dissection (ESD). EMR removes 1.5-2 $\mathrm{cm}$ diameter pieces of the esophageal mucosa, and it can be used alone to remove shorter Barrett's esophagus segments, or as an adjunct to other ablative therapies, such as RFA. It is often used for small excisional biopsies $(<2 \mathrm{~cm})$ of mucosal irregularities or nodules. Benefits of EMR include deeper tissue removal and a larger and deeper biopsy specimen than can be achieved with standard biopsy forceps. This facilitates more accurate histological evaluation of visible early lesions within Barrett's esophagus segments. ${ }^{54}$ Using EMR alone to eradicate circumferential Barrett's esophagus has been described, although many studies report complications. The efficacy of EMR for complete eradication has been reported to range from $76 \%$ to $100 \%,{ }^{55-57}$ but relevant complications include bleeding and perforations, with strictures occurring in up to half of the treated patients after circumferential resections. ${ }^{55-59}$ ESD achieves, compared to EMR, a more extensive "en bloc" resection of the mucosa. This technique is technically more challenging, and a direct comparison with EMR has shown similar eradication rates for dysplasia and intramucosal adenocarcinoma, but with a longer procedure duration and higher postprocedure stenosis rate ( $44 \%$ vs $20 \%)$ following ESD. The costs of ESD are nearly double of that of EMR and associated with a significant learning curve. ${ }^{49}$ For these reasons, EMR is the more popular technique in Western countries.

It is also important to remember that surgical resection of esophageal cancer is an effective treatment for early-stage cancer and HGD, and offers a single-step definitive treatment which will be curative, and unlike endoscopic ablation, ongoing endoscopic surveillance after treatment is no longer needed. However, surgery is not feasible in individuals with significant comorbidities, and it is associated with significant perioperative morbidity, mortality risk, and reduced quality of life in the early follow-up period. ${ }^{50,60-62}$ Nevertheless, esophagectomy performed for HGD or intramucosal cancer is a lower risk procedure than when undertaken for advanced cancer, with lower mortality outcomes of approximately
$1 \%-2 \%$ in this patient group. ${ }^{63,64}$ However, there is no doubt that endoscopic treatments preserve the normal esophageal anatomy, are safer, and are associated with lower morbidity and mortality than esophagectomy, and for these reasons endoscopic interventions are replacing surgery as first-line therapy in patients with HGD or intramucosal cancer.

\section{RFA - implications, results, and outcome \\ Background}

RFA has recently become the most widely used approach for the treatment of dysplastic Barrett's esophagus. It has been described as a treatment for all "stages" of the disease. RFA was originally used for treatment of HGD and intramucosal adenocarcinoma, but more recently it has been used for LGD and nondysplastic Barrett's esophagus (NDBE), as well as an adjunct in combination with EMR, with EMR being used for treatment of nodular lesions, and RFA for removal of the remainder of the Barrett's esophagus, thereby minimizing the risk of complications of EMR.

From a technical aspect, RFA uses bipolar electrical energy to thermally destroy the Barrett's esophagus mucosa. A balloon catheter containing a $360^{\circ}$ radiofrequency array is inserted, inflated in the esophagus, and then activated to deliver radiofrequency energy, which heats intracellular water to kill affected cells. Both $60^{\circ}$ and $90^{\circ}$ catheters are available, although most authors report using the HALO 360 system (Covidien, Sunnyvale, CA, USA). The HALO 90 and HALO 60 systems tend to be used for Barrett's "tongues", residual "islands", or shorter segments of Barrett's esophagus. The HALO 360 is a cylindrical balloon used to treat circumferential Barrett's esophagus at one time over a distance of up to $3 \mathrm{~cm}$, but longer segments are treatable using multiple overlapping treatments. The amount of energy used for dysplastic lesions is approximately $12-15 \mathrm{~J} / \mathrm{cm}^{2}$, and nondysplastic mucosa is treated with approximately $10 \mathrm{~J} / \mathrm{cm}^{2}$. The depth of destruction is approximately $1,000 \mu \mathrm{m}$, and this is generally sufficient to destroy nonnodular, ie, "flat" Barrett's dysplasia ${ }^{49}$ It is important to stress that RFA treatment in the context of intramucosal adenocarcinoma is only feasible for "flat" Barrett's esophagus segments, with no nodular mucosal abnormalities. Nodular mucosal abnormalities should be considered for EMR prior to application of RFA.

RFA is usually delivered as an outpatient procedure and can be applied across several repeated sessions. Hence, RFA allows treatment of longer segments of Barrett's esophagus via extended and/or circumferential destruction of tissue in a relatively short period of time. Furthermore, this technique 
has been shown to be less costly than other interventions such as PDT, when taking cost, efficiency, and the number of treatment sessions required into consideration. ${ }^{65}$ With regard to complications of the initial treatment and the need for further posttreatment interventions to deal with these problems, RFA seems to be superior to EMR. For example, the rate of esophageal strictures is much higher after EMR, and the number of dilations needed in EMR patients exceeds that required for post-RFA strictures. Thus, even though more endoscopies are required with RFA to achieve complete eradication of Barrett's esophagus, more endoscopies might be required to resolve complications arising from EMR. ${ }^{66}$ Finally, RFA is technically much easier to perform than other modalities such as EMR. ${ }^{67}$

\section{Elimination of Barrett's esophagus following RFA}

Ablative treatments, such as RFA, for (dysplastic) Barrett's esophagus aim to prevent progression to cancer by eliminating the precursor lesions. Efficacy of this treatment can be estimated by its ability to successfully eradicate the abnormal, metaplastic cells of Barrett's esophagus. A number of randomized and nonrandomized trials have shown promising results with regard to complete eradication of the Barrett's esophagus. Overall, complete eradication of intestinal metaplasia has been reported to be achieved in 54\%-100\% of cases, ${ }^{14,66,68-73}$ and compete eradication of dysplastic lesions has been achieved in $83 \%-100 \%$ cases. ${ }^{14,68-71,73}$

Shaheen et $\mathrm{al}^{68}$ reported the first randomized trial to address RFA. In a multicenter, sham-controlled trial they randomly assigned 127 patients with dysplastic Barrett's esophagus to RFA vs surveillance (2:1), and followed the patients for 12 months. Approximately half the patients had HGD at entry in to the trial, and the remaining half had LGD. For the individuals with LGD, complete eradication was achieved in $90.5 \%$ of patients treated with RFA vs $22.7 \%$ of the control group. The rate of eradication of HGD was slightly less, but still significantly different for the two groups, with $81.0 \%$ of the patients achieving complete eradication following RFA compared to $19.0 \%$ in the control group. ${ }^{68}$ In a nonrandomized study, Sharma et al ${ }^{14}$ reported similar results. They treated 67 patients with RFA, and for the cohort with LGD, the rates of complete eradication of intestinal metaplasia and dysplasia were reported to be $87 \%$ and $95 \%$, respectively. In the HGD cohort, the rates of eradication were $67 \%$ for intestinal metaplasia and $79 \%$ for dysplasia. ${ }^{14}$

More recently, a second multicenter randomized clinical trial was reported by Phoa et al. ${ }^{74}$ This trial evaluated
RFA in a cohort of 136 individuals with LGD. Half of the patients were treated with endoscopic RFA, and the other half underwent surveillance. Complete eradication of LGD and intestinal metaplasia was achieved in $92.6 \%$ and $88.2 \%$ of patients, respectively. ${ }^{74}$ Other smaller studies included one by Perry et $\mathrm{al}^{75}$ who followed 19 patients with nodules in HGD for 3 years, following EMR for resection of nodular lesions and concurrent RFA for the remaining Barrett's esophagus. Complete eradication of HGD was achieved in $88 \%$ of these individuals. ${ }^{75}$ In 61 patients treated with RFA for Barrett's esophagus without dysplasia, Fleischer et $\mathrm{al}^{76}$ achieved complete eradication in $98.4 \%$, with efficacy persisting over the entire study period of 2.5 years.

The data from all of these studies clearly show that RFA has a high success rate for complete eradication of nondysplastic and dysplastic (LGD and HGD) Barrett's esophagus, although, eradication of visible Barrett's esophagus does not necessarily equate to cancer prevention.

\section{Recurrence and disease progression}

As RFA ablation of (dysplastic) Barrett's esophagus does not remove the entire esophagus, and the regenerated postablation squamous mucosa probably arises from stem cells lying underneath the original Barrett's esophagus, there are some concerns about whether ablation treatments remove all diseased tissue reliably to prevent recurrence of Barrett's esophagus or progression to cancer. Reported rates of recurrence of Barrett's esophagus following RFA ablation are variable, ranging from $0 \%$ to $32 \% .^{66,76,77}$ Different study parameters such as study size and duration of follow-up might contribute to this variation. For example, most studies report a follow-up period of 1-2 years, and as recurrence probably progresses over time, studies with a short follow-up period might underestimate the risk of recurrence. Furthermore, the definition of recurrence varies between studies, with some including recurrences at the gastroesophageal junction (GEJ), whereas others defined recurrence as a biopsyproven lesion from above the GEJ, arising within the tubular esophagus. ${ }^{78}$ There is also no agreed definition of how many negative endoscopies are finally required to prove "complete remission".

Vaccaro et $\mathrm{al}^{70}$ followed up 47 patients for up to 38 months, following complete eradication of NDBE, and 15 (32\%) of them developed recurrent metaplasia. The median time to detection of recurrence was 9 months. Of the 15 patients with recurrence, 4 presented with disease progression: 2 developed LGD, and 2 developed HGD. Interestingly, dysplastic mucosa was only found at the site of the GEJ ${ }^{70}$ Gupta et al ${ }^{79}$ 
reported outcomes from a multicenter study which enrolled 229 patients from three US centers. In this series, 33\% of patients developed recurrence of intestinal metaplasia, all following previous RFA treatment (with or without prior EMR) with complete eradication. Eighteen patients presented with recurrence in the tubular esophagus alone, and 17 developed recurrence at the GEJ alone. Two patients finally developed recurrence at both sites simultaneously. Most of the recurrences were nondysplastic lesions. However, $8 \%$ of patients were found to have LGD, 11\% had HGD, and 3\% had adenocarcinoma on histology. ${ }^{79}$

Some studies have tried to identify risk factors for recurrence following ablation. The length of the Barrett's esophagus segment seems to be associated with higher rates of recurrence. ${ }^{67,70,80,81}$ For example, at 3 years follow-up, recurrent intestinal metaplasia was reported in $18 \%$ of patients who underwent ablation of long segment Barrett's esophagus (mean length, $4.7 \mathrm{~cm}$ ) vs $35 \%$ of patients with ultralong segment disease (mean length, $10.8 \mathrm{~cm}$ ), although none of the recurrences in this study were associated with dysplasia. ${ }^{81}$ However, it has also been hypothesized that these patients did not actually have recurrent Barrett's esophagus after complete eradication, but rather presented with "recurrent" disease from so-called buried islands of Barrett's esophagus which were not successfully ablated during initial treatment, ie, the original Barrett's esophagus was not fully eradicated. ${ }^{78}$

Two randomized-controlled trials have evaluated the progression of Barrett's esophagus to HGD or cancer following RFA treatment. In the first study, Shaheen et al ${ }^{68}$ investigated disease progression, which was defined as either HGD progressing to cancer or LGD progressing to HGD or cancer. In the second trial, Phoa et $\mathrm{al}^{74}$ investigated disease progression only in patients diagnosed with LGD in Barrett's esophagus.

Shaheen et $\mathrm{l}^{68}$ reported promising data supporting a reduction in the risk of progression following RFA. In this trial, the authors reported overall progression of disease in $3.6 \%$ of patients following RFA vs $16.3 \%$ of controls undergoing endoscopy surveillance. Disease progression was defined as either HGD progressing to cancer or LGD progressing to HGD or cancer. RFA treatment was followed by a significantly reduced rate of progression from HGD to cancer at 12 months follow-up, and in the subgroup who had HGD at enrollment, $2.4 \%$ progressed to cancer following RFA vs $19 \%$ of controls $(P=0.04)$. Interestingly, in the subgroup of patients with LGD at enrollment, progression to HGD was not significantly different following RFA ablation compared to controls; $4.8 \%$ following RFA vs $13.6 \%$ in controls ( $P=0.33$ ), and no patient with LGD progressed to cancer. ${ }^{68}$ The overall rate of recurrent Barrett's esophagus, however, was more difficult to assess as the authors offered all of the control (surveillance) patients RFA treatment following the initial 12 months follow-up, and all patients accepted this treatment. ${ }^{80}$ Hence, the subsequent report of 2 years follow-up did not provide randomized data at the later follow-up point, although $95 \%$ of all patients were reported to have maintained complete eradication of dysplasia at 2 years. ${ }^{80}$

In the second randomized trial, Phoa et $\mathrm{al}^{74}$ reported 3-year follow-up data from a trial which randomized patients diagnosed with LGD in Barrett's esophagus to RFA ablation vs endoscopic surveillance. Within the group of 68 patients treated by RFA, eradication of dysplasia was achieved in $63(92.6 \%)$, and only 1 patient $(1.6 \%)$ had recurrent Barrett's esophagus at follow-up. For intestinal metaplasia, the success rate was a bit lower, with $60(88.2 \%)$ achieving complete eradication and $54(79.4 \%)$ still eradicated at follow-up. All recurrences found in the ablation group were described as small islands or tongues of Barrett's esophagus, measuring less than $10 \mathrm{~mm}$ in extent. Of significance, progression from LGD to HGD or adenocarcinoma was seen in $1.5 \%(\mathrm{n}=1)$ of patients in the ablation group vs $26.5 \%(n=18)$ of controls $(P<0.001)$. More specifically, progression to adenocarcinoma was seen in $1.5 \%$ of patients following RFA vs $8.8 \%$ in the control group $(P=0.03)$. The authors concluded a reduction of risk of progression to cancer of $7.4 \%$ following RFA. ${ }^{74}$ This rate of disease progression from LGD to HGD or cancer contrast with the findings of Shaheen et $\mathrm{a}^{68}$ who reported that RFA treatment had no significant impact on progression in patients with LGD. However, it is important to note that in Phoa et al's ${ }^{74}$ trial, the definition of LGD was different from the standard definition of LGD used in community practice. For entry into this trial, the diagnosis of LGD was required to be confirmed by an "expert central pathology panel", and this led to the exclusion of 264 of the 511 patients who were initially considered for the trial, and ultimately only 140 of the 511 patients considered for the trial were actually enrolled. At 12 months follow-up, the rate of progression from LGD to HGD or cancer was reported to be approximately $15 \%$. This downstaging of many of the patients initially diagnosed with LGD, resulting in a higher rate of disease progression in those remaining with "confirmed" LGD, has been replicated in two recent studies from the Netherlands. Following review by an "expert panel of pathologists", Curvers et al ${ }^{82}$ reported downstaging of $85 \%$ of their patients from an initial diagnosis of LGD to NDBE or to IND. Interestingly, in the 
group of patients with a consensus diagnosis of LGD, the cumulative risk of progressing to HGD or cancer across a follow-up period of 9 years was $85.0 \%$ compared to $4.6 \%$ in patients downstaged to NDBE $(P<0.0001)$. This equated to a progression rate to HGD or cancer of $13.4 \%$ per year for LGD vs $0.49 \%$ per year for NDBE. ${ }^{82}$ For patients with an "expert diagnosis" of LGD, the risk of progression to HGD or cancer was $9.1 \%$ per year compared to $0.6 \%$ and $0.9 \%$ in NDBE or IND. ${ }^{83}$ These very high rates of progression confirm that the pathology screening process applied in the Phoa et al's trial ${ }^{74}$ and in other studies using "expert panel pathology review" selected out a subgroup of patients with LGD who have a much higher risk of progression to HGD or cancer. Hence, it is difficult to generalize these results to the wider clinical environment where less stringent criteria are used for the diagnosis of LGD. For this reason, recent Australian recommendations for the treatment of Barrett's esophagus have limited their recommendation for ablation to HGD and intramucosal cancer, and have not broadened this to LGD. ${ }^{23}$ However, in centers which can provide the necessary "expert panel pathology review", RFA might now be justified in patients with confirmed LGD.

In summary, reported data suggest that following RFA ablation for dysplastic Barrett's esophagus, up to one-third of patients might develop at least some recurrent Barrett's esophagus mucosa, and the longer term status of this recurrent mucosa is unknown. With regard to the questions of progression and cancer prevention, the two randomized controlled trials provide important evidence that suggests that the risk of progression to a higher grade of dysplasia or cancer is reduced following RFA ablation, although this risk is not completely eliminated. However, follow-up in these trials remains short, and there is currently no longterm survival data supporting RFA ablation of dysplastic Barrett's esophagus. As most larger studies report recurrent HGD or cancer progression following RFA ablation, albeit at a low rate, ongoing endoscopy surveillance is still required after ablation, and for this reason, ablation should only be performed in individuals who are able to comply with postablation follow-up protocols.

\section{Potential limitations of RFA in the clinical context}

There are some limitations to the use of RFA for the treatment of dysplastic Barrett's esophagus. One significant disadvantage is that a pathology specimen is not obtained for histopathological examination. This means that there is some uncertainty about staging, grading, and completeness of eradication of intramucosal cancers if RFA is used as the only treatment modality. Combined treatment with EMR of visible mucosal lesions might reduce the risk of this problem, although understaging might lead to undertreatment of cancers if care in workup is not taken. If a stage $\mathrm{T} 1 \mathrm{~b}$ cancer is present, with invasion into the submucosa, then the risk of lymph node metastasis is significant, ${ }^{84,85}$ and endoscopic therapies will undertreat many individuals. Additional problems can occur with RFA in the context of very long segments of Barrett's esophagus, ablation in the presence of an esophageal stricture, and lesions close to the GEJ in hiatus hernia. In the latter scenarios, adequate ablation can be difficult.

\section{Complications of RFA}

Like any interventional procedure, RFA also has the potential to cause harm (Table 2). Clinical benefit depends on the balance of proposed benefits vs side effects and complications. Reported complications and side effects include chest pain, mucosal lacerations, upper gastrointestinal hemorrhage, and esophageal stricture. Of these problems, chest pain is the most commonly reported problem, and it probably occurs as a consequence of ulceration of the esophageal mucosa following the deliberate mucosa injury caused by RFA. Immediate chest pain following therapy has been reported in 5\%-28\% of patients undergoing treatment, and this usually resolves within 3-5 days. ${ }^{14,66,68-73}$ Rarely, chest pain has been reported to be associated with nausea, or requires overnight stay in hospital. ${ }^{68,72}$ Mucosal lacerations can occur following inflation of the balloon device, and these occur relatively commonly, although mucosal injury is reported to be rarely deep enough to cause perforation. ${ }^{86}$ Two cases

Table 2 Outcomes and complications following radiofrequency ablation

\begin{tabular}{ll}
\hline Outcomes & \\
Eradication of intestinal metaplasia & $54 \%-100 \%$ \\
Eradication of dysplastic lesions & $83 \%-100 \%$ \\
Recurrence of Barrett's esophagus & $0 \%-32 \%$ \\
Progression of disease compared & $1.5 \%$ vs $26.5 \%^{\mathrm{a}}$ \\
to controls & $3.6 \%$ vs $16.3 \%^{\mathrm{b}}$ \\
Complications & \\
Chest pain & $5 \%-28 \%$ \\
Mucosal lacerations & Relatively common \\
Stricture & $0 \%-14 \%$ \\
Hemorrhage requiring intervention & Rare \\
\hline
\end{tabular}

Notes: aExpert panel pathology review confirmed progression of LGD to HGD or adenocarcinoma; ${ }^{73}$ progression of disease determined when HGD progressed to cancer or LGD progressed to HGD or cancer..$^{79}$ These data are sourced from published randomized controlled trials.

Abbreviations: LGD, low-grade dysplasia; HGD, high-grade dysplasia. 
of significant acute upper gastrointestinal hemorrhage have been reported. Both of these patients were on dual antiplatelet therapy for heart disease, and both required endoscopic treatment for the bleeding. ${ }^{14,68}$ A further report describes a patient with delayed bleeding, presenting with melena after recommencing anticoagulation for atrial fibrillation. In this instance, bleeding was treated by endoscopy, injection with adrenaline, and blood transfusion. ${ }^{66}$

Esophageal stricture, defined as a narrowing of the esophagus with or without dysphagia, seen during follow-up endoscopy is a reported late complication. The incidence of this problem is reported to range from $0 \%$ to $14 \% .^{14,66,68,69,71-74,77}$ As the depth of injury is generally shallower after RFA, with the muscularis mucosae and submucosa generally remaining intact, the risk of stricture is lower than following circumferential EMR or ESD. ${ }^{49,50}$ For example, stricture rates after total endoscopic mucosa resections have been reported to be as high as up to $88 \%,{ }^{66}$ and these strictures are described as more severe and require more dilatations than strictures caused by RFA. ${ }^{49}$ Strictures from RFA have generally been reported to resolve with endoscopic dilation in 1-3 sessions. ${ }^{66,68,74}$

In summary, morbidity after RFA is reported to be relatively low with the most frequent complication being chest pain. Postinterventional strictures are the most important postinterventional complication and occur in up to $14 \%$ of patients, and some of these require further endoscopic treatment. However, compared to endoscopic mucosal excision technique, the risk of stricture is lower and treatment easier.

\section{Does RFA really eliminate Barrett's esophagus?}

As described above, several studies have clearly demonstrated that RFA can achieve a high rate of complete eradication of Barrett's esophagus. This suggests that dysplastic Barrett's esophagus can be well treated by RFA, and RFA can completely eliminate all metaplastic or dysplastic tissue. However, there is an ongoing debate about so called "buried islands" of Barrett's esophagus. Metaplastic or dysplastic cells might also be found in "buried islands" underneath the regenerated, apparently normal squamous epithelium. These buried islands represent metaplastic Barrett's cells that are found under the epithelium in the lamina propria, and these islands are hidden at endoscopy as the surface of the mucosa appears macroscopically as normal squamous mucosa. These islands can only be detected by chance if a biopsy is taken of the squamous mucosa that is overlying the buried glands. It has been hypothesized that these buried glands are a result of either incomplete ablation (buried glands being deeper than the superficial layer) or a consequence of extensive biopsy sampling during surveillance. ${ }^{78}$ The rate of detection of buried glands varies from $0 \%$ to $5 \% .{ }^{14,68}$ While there are no studies which evaluate the risk of progression to cancer from these buried islands, there have been isolated case reports of cancers developing within these islands. ${ }^{87,88}$ Importantly, however, buried glands are not unique to patients who have undergone RFA ablation, as they were previously identified after PDT, APC, and multipolar electrocoagulation interventions. ${ }^{89}$ A proposed advantage for RFA ablation was that this problem would be eliminated by RFA. However, this appears to have not been realized.

Another potential consideration is whether or not the neosquamous epithelium that repopulates the tubular esophagus after RFA ablation is a functionally normal squamous epithelium. Following ablation, it is likely that the neosquamous epithelium regenerates from local stem cells within the esophageal wall, and not from proximal to distal ingrowth from normal proximal squamous mucosa. There is debate about whether the new epithelium is comparable to normal squamous epithelium, or whether it is functionally more like Barrett's metaplasia. Dunkin et $\mathrm{al}^{90}$ investigated samples from above the previously diseased area and from the neosquamous epithelium from patients who underwent RFA treatment. The neosquamous epithelium showed, compared to normal epithelium, downregulation of claudin- 4 with subsequently increased permeability to cations. This resulted in a less effective barrier to refluxing stomach acids..$^{90}$ Other studies have investigated genetic changes in neosquamous epithelium following ablation, ${ }^{91-94}$ and suggested that neosquamous epithelium following RFA might be genetically closer to the original squamous epithelium, compared to the neosquamous epithelium that repopulates the esophagus after other ablation therapies such as PDT and APC. ${ }^{50,94}$

Taken together, there appears to be some risk of progression to cancer remaining even after successful ablation of Barrett's esophagus with RFA. The actual rate of recurrence of Barrett's esophagus or risk of cancer progression is unknown, and until larger studies with longer term followup are available, it will be important to manage the risk of problems arising after ablation, even though this risk is almost certainly less than the risk associated with nonablated dysplastic Barrett's esophagus. This mandates ongoing endoscopy surveillance following ablation, and this issue might impact adversely on the eventual cost-effectiveness of RFA ablation. 


\section{Conclusion}

RFA is an endoscopic technique for ablation of Barrett's esophagus that has been developed in recent years, aiming to prevent progression from Barrett's esophagus to cancer. This technique is simple to use and allows treatment of short and long segments of Barrett's esophagus via extended and/or circumferential destruction of tissue in a short period of time. The technique is safe and associated with acceptable morbidity.

Current literature demonstrates that RFA is a highly successful treatment for nondysplastic and dysplastic (LGD and HGD) Barrett's esophagus, achieving complete eradication in most individuals. In addition, the literature suggests that the risk of progression to higher grades of dysplasia or cancer is reduced following RFA ablation, although the risk of cancer is not completely eliminated. Current evidence supports the use of RFA ablation in individuals with HGD or intramucosal cancer, although it is probably premature to recommend routine RFA ablation for individuals with a community diagnosis of LGD, although this recommendation may not hold if "expert" pathology review is available. There is no evidence to support the use of RFA ablation for NDBE.

Unfortunately, however, eradication of visible Barrett's esophagus does not necessarily mean that the treatment has been successful. Up to one-third of patients might develop recurrent Barrett's esophagus mucosa, and there is a risk of "buried glands" that represent islands of Barrett's mucosa beneath the new esophageal mucosa. In addition, the neosquamous epithelium after RFA might not be a "normal" squamous epithelium and might still harbor some ongoing risk of cancer progression. Currently, there is a lack of good long-term follow-up data after RFA ablation, and in the absence of data, the potential for RFA to effectively prevent cancer progression across the long-term is still uncertain, and all treated individuals currently need to remain on an endoscopy surveillance program.

However, RFA ablation is a promising option for the treatment of Barrett's esophagus with HGD or intramucosal cancer, and the early data are promising with regard to the future risk of cancer progression. Large-scale studies with long-term follow-up will be needed to fully determine the ability of this approach to reliably reduce the risk of cancer development in Barrett's esophagus.

\section{Disclosure}

The authors report no conflicts of interest in this work.

\section{References}

1. Lord RV, Law MG, Ward RL, Giles GG, Thomas RJ, Thursfield V. Rising incidence of oesophageal adenocarcinoma in men in Australia. J Gastroenterol Hepatol. 1998;13(4):356-362.
2. Hansson LE, Sparen P, Nyren O. Increasing incidence of both major histological types of esophageal carcinomas among men in Sweden. Int J Cancer. 1993;54(3):402-407.

3. Pohl H, Welch HG. The role of overdiagnosis and reclassification in the marked increase of esophageal adenocarcinoma incidence. $J$ Natl Cancer Inst. 2005;97(2):142-146.

4. Kendall BJ, Whiteman DC. Temporal changes in the endoscopic frequency of new cases of Barrett's esophagus in an Australian health region. Am J Gastroenterol. 2006;101(6):1178-1182.

5. Hameeteman W, Tytgat GN, Houthoff HJ, van den Tweel JG. Barrett's esophagus: development of dysplasia and adenocarcinoma. Gastroenterology. 1989;96(5 Pt 1):1249-1256.

6. Alexandropoulou K, van Vlymen J, Reid F, Poullis A, Kang JY. Temporal trends of Barrett's oesophagus and gastro-oesophageal reflux and related oesophageal cancer over a 10-year period in England and Wales and associated proton pump inhibitor and H2RA prescriptions: a GPRD study. Eur J Gastroenterol Hepatol. 2013;25(1):15-21.

7. Bhat S, Coleman HG, Yousef F, et al. Risk of malignant progression in Barrett's esophagus patients: results from a large population-based study. J Natl Cancer Inst. 2013;103(13):1049-1057.

8. Hvid-Jensen F, Pedersen L, Drewes AM, Sorensen HT, Funch-Jensen P. Incidence of adenocarcinoma among patients with Barrett's esophagus. N Engl J Med. 2011;365(15):1375-1383.

9. Murray L, Watson P, Johnston B, Sloan J, Mainie IM, Gavin A. Risk of adenocarcinoma in Barrett's oesophagus: population based study. BMJ. 2003;327(7414):534-535.

10. Schouten LJ, Steevens J, Huysentruyt CJ, et al. Total cancer incidence and overall mortality are not increased among patients with Barrett's esophagus. Clin Gastroenterol Hepatol. 2011;9(9):754-761.

11. Buttar NS, Wang KK, Sebo TJ, et al. Extent of high-grade dysplasia in Barrett's esophagus correlates with risk of adenocarcinoma. Gastroenterology. 2001;120(7):1630-1639.

12. Reid BJ, Blount PL, Feng Z, Levine DS. Optimizing endoscopic biopsy detection of early cancers in Barrett's high-grade dysplasia. Am J Gastroenterol. 2000;95(11):3089-3096.

13. Cameron AJ, Zinsmeister AR, Ballard DJ, Carney JA. Prevalence of columnar-lined (Barrett's) esophagus. Comparison of population-based clinical and autopsy findings. Gastroenterology. 1990;99(4):918-922.

14. Sharma VK, Jae Kim H, Das A, Wells CD, Nguyen CC, Fleischer DE. Circumferential and focal ablation of Barrett's esophagus containing dysplasia. Am J Gastroenterol. 2009;104(2):310-317.

15. Kubo A, Cook MB, Shaheen NJ, et al. Sex-specific associations between body mass index, waist circumference and the risk of Barrett's oesophagus: a pooled analysis from the international BEACON consortium. Gut. 2013;62(12):1684-1691.

16. Singh S, Sharma AN, Murad MH, et al. Central adiposity is associated with increased risk of esophageal inflammation, metaplasia, and adenocarcinoma: a systematic review and meta-analysis. Clin Gastroenterol Hepatol. 2013;11(11):1399-1412. e7.

17. Cook MB, Shaheen NJ, Anderson LA, et al. Cigarette smoking increases risk of Barrett's esophagus: an analysis of the Barrett's and Esophageal Adenocarcinoma Consortium. Gastroenterology. 2012;142(4): $744-753$.

18. Cook MB, Wild CP, Forman D. A systematic review and meta-analysis of the sex ratio for Barrett's esophagus, erosive reflux disease, and nonerosive reflux disease. Am J Epidemiol. 2005;162(11):1050-1061.

19. Corley DA, Kubo A, Levin TR, et al. Race, ethnicity, sex and temporal differences in Barrett's oesophagus diagnosis: a large community-based study, 1994-2006. Gut. 2009;58(2):182-188.

20. Chak A, Lee T, Kinnard MF, et al. Familial aggregation of Barrett's oesophagus, oesophageal adenocarcinoma, and oesophagogastric junctional adenocarcinoma in Caucasian adults. Gut. 2002;51(3): 323-328.

21. Whiteman DC, Sadeghi S, Pandeya N, et al. Combined effects of obesity, acid reflux and smoking on the risk of adenocarcinomas of the oesophagus. Gut. 2008;57(2):173-180. 
22. Basu KK, Bale R, West KP, de Caestecker JS. Persistent acid reflux and symptoms in patients with Barrett's oesophagus on proton-pump inhibitor therapy. Eur J Gastroenterol Hepatol. 2002;14(11):1187-1192.

23. Whiteman DC, Appleyard M, Bahin FF, et al. Australian clinical practice guidelines for the diagnosis and management of Barrett's esophagus and early esophageal adenocarcinoma. J Gastroenterol Hepatol. 2015;30(5):804-820.

24. Fitzgerald RC, di Pietro M, Ragunath K, et al. British Society of Gastroenterology guidelines on the diagnosis and management of Barrett's oesophagus. Gut. 2014;63(1):7-42.

25. Spechler SJ, Sharma P, Souza RF, Inadomi JM, Shaheen NJ. American Gastroenterological Association medical position statement on the management of Barrett's esophagus. Gastroenterology. 2011;140(3): 1084-1091.

26. Spechler SJ, Sharma P, Souza RF, Inadomi JM, Shaheen NJ. American Gastroenterological Association technical review on the management of Barrett's esophagus. Gastroenterology. 2011;140(3):e18-e52; quiz e13.

27. Rubenstein JH, Sonnenberg A, Davis J, McMahon L, Inadomi JM. Effect of a prior endoscopy on outcomes of esophageal adenocarcinoma among United States veterans. Gastrointest Endosc. 2008;68(5):849-855.

28. Frazzoni M, Manno M, De Micheli E, Savarino V. Efficacy in intraoesophageal acid suppression may decrease after 2-year continuous treatment with proton pump inhibitors. Dig Liver Dis. 2007;39(5):415-421.

29. Sharma P, Sampliner RE, Camargo E. Normalization of esophageal $\mathrm{pH}$ with high-dose proton pump inhibitor therapy does not result in regression of Barrett's esophagus. Am J Gastroenterol. 1997;92(4): $582-585$.

30. Singh S, Garg SK, Singh PP, Iyer PG, El-Serag HB. Acid-suppressive medications and risk of oesophageal adenocarcinoma in patients with Barrett's oesophagus: a systematic review and meta-analysis. Gut. 2014; 63(8):1229-1237.

31. Rees JR, Lao-Sirieix P, Wong A, Fitzgerald RC. Treatment for Barrett's oesophagus. Cochrane Database Syst Rev. 2010;(1):CD004060.

32. Attwood SE, Lundell L, Hatlebakk JG, et al. Medical or surgical management of GERD patients with Barrett's esophagus: the LOTUS trial 3-year experience. J Gastrointest Surg. 2008;12(10):1646-1654; discussion 54-55.

33. Zehetner J, DeMeester SR, Ayazi S, et al. Long-term follow-up after anti-reflux surgery in patients with Barrett's esophagus. J Gastrointest Surg. 2010;14(10):1483-1491.

34. Yau P, Watson DI, Devitt PG, Game PA, Jamieson GG. Laparoscopic antireflux surgery in the treatment of gastroesophageal reflux in patients with Barrett esophagus. Arch Surg. 2000;135(7):801-805.

35. Wassenaar EB, Oelschlager BK. Effect of medical and surgical treatment of Barrett's metaplasia. World J Gastroenterol. 2010;16(30): 3773-3779.

36. Parrilla P, Martinez de Haro LF, Ortiz A, et al. Long-term results of a randomized prospective study comparing medical and surgical treatment of Barrett's esophagus. Ann Surg. 2003;237(3):291-298.

37. Ye W, Chow WH, Lagergren J, Yin L, Nyren O. Risk of adenocarcinomas of the esophagus and gastric cardia in patients with gastroesophageal reflux diseases and after antireflux surgery. Gastroenterology. 2001; 121(6):1286-1293.

38. Tran T, Spechler SJ, Richardson P, El-Serag HB. Fundoplication and the risk of esophageal cancer in gastroesophageal reflux disease: a Veterans Affairs cohort study. Am J Gastroenterol. 2005;100(5):1002-1008.

39. Lord RV. Does antireflux surgery prevent progression of Barrett's esophagus? Minerva Chir. 2011;66(1):1-6.

40. National Institute for Health and Clinical Excellence. Epithelial Radiofrequency Ablation for Barrett's Oesophagus. London, UK: National Institute for Health and Clinical Excellence; 2010.

41. Sampliner RE, Fennerty B, Garewal HS. Reversal of Barrett's esophagus with acid suppression and multipolar electrocoagulation: preliminary results. Gastrointest Endosc. 1996;44(5):532-535.

42. Wolfsen HC. Endoluminal therapy for Barrett's esophagus. Gastrointest Endosc Clin N Am. 2007;17(1):59-82, vi-vii.
43. Gurgacz SCJ, Cameron A, Goodall S. Radiofrequency ablation for Barrett's oesophagus with dysplasia. Assessment Report. Canberra, ACT: Commonwealth of Australia; 2010.

44. Sie C, Bright T, Schoeman M, et al. Argon plasma coagulation ablation versus endoscopic surveillance of Barrett's esophagus: late outcomes from two randomized trials. Endoscopy. 2013;45(11):859-865.

45. Van Laethem JL, Cremer M, Peny MO, Delhaye M, Deviere J. Eradication of Barrett's mucosa with argon plasma coagulation and acid suppression: immediate and mid term results. Gut. 1998;43(6):747-751.

46. Bright T, Watson DI, Tam W, et al. Prospective randomized trial of argon plasma coagulation ablation versus endoscopic surveillance of Barrett's esophagus in patients treated with antisecretory medication. Dig Dis Sci. 2009;54(12):2606-2611.

47. Bright T, Watson DI, Tam W, et al. Randomized trial of argon plasma coagulation versus endoscopic surveillance for barrett esophagus after antireflux surgery: late results. Ann Surg. 2007;246(6): 1016-1020.

48. Ackroyd R, Tam W, Schoeman M, Devitt PG, Watson DI. Prospective randomized controlled trial of argon plasma coagulation ablation vs endoscopic surveillance of patients with Barrett's esophagus after antireflux surgery. Gastrointest Endosc. 2004;59(1):1-7.

49. Aranda-Hernandez J, Cirocco M, Marcon N. Treatment of dysplasia in barrett esophagus. Clin Endosc. 2014;47(1):55-64.

50. Mayne GC, Bright T, Hussey DJ, Watson DI. Ablation of Barrett's oesophagus: towards improved outcomes for oesophageal cancer? ANZ J Surg. 2012;82(9):592-598.

51. Kelty CJ, Ackroyd R, Brown NJ, Stephenson TJ, Stoddard CJ, Reed MW. Endoscopic ablation of Barrett's oesophagus: a randomizedcontrolled trial of photodynamic therapy vs argon plasma coagulation. Aliment Pharmacol Ther. 2004;20(11-12):1289-1296.

52. Overholt BF, Lightdale CJ, Wang KK, et al. Photodynamic therapy with porfimer sodium for ablation of high-grade dysplasia in Barrett's esophagus: international, partially blinded, randomized phase III trial. Gastrointest Endosc. 2005;62(4):488-498.

53. Wang KK. Photodynamic therapy of Barrett's esophagus. Gastrointest Endosc Clin NAm. 2000;10(3):409-419.

54. Peters JH, Watson TA. Endoscopic mucosal resection of Barrett's esophagus and early esophageal cancer. J Gastrointest Surg. 2011;15(8): 1299-1302.

55. Chennat J, Konda VJ, Ross AS, et al. Complete Barrett's eradication endoscopic mucosal resection: an effective treatment modality for high-grade dysplasia and intramucosal carcinoma - an American singlecenter experience. Am J Gastroenterol. 2009;104(11):2684-2692.

56. Pouw RE, Seewald S, Gondrie JJ, et al. Stepwise radical endoscopic resection for eradication of Barrett's oesophagus with early neoplasia in a cohort of 169 patients. Gut. 2010;59(9):1169-1177.

57. Pech O, May A, Manner H, et al. Long-term efficacy and safety of endoscopic resection for patients with mucosal adenocarcinoma of the esophagus. Gastroenterology. 2014;146(3):652-660. e1.

58. Chung A, Bourke MJ, Hourigan LF, et al. Complete Barrett's excision by stepwise endoscopic resection in short-segment disease: long term outcomes and predictors of stricture. Endoscopy. 2011;43(12): $1025-1032$

59. Lopes CV, Hela M, Pesenti C, et al. Circumferential endoscopic resection of Barrett's esophagus with high-grade dysplasia or early adenocarcinoma. Surg Endosc. 2007;21(5):820-824.

60. Bennett C, Green S, Barr H, et al. Surgery versus radical endotherapies for early cancer and high grade dysplasia in Barrett's oesophagus. Cochrane Database Syst Rev. 2010;(5):CD007334.

61. National Institute for Health and Clinical Excellence. Thorascopically Assisted Oesophagectomy (IPG189). London, UK: National Institute for Health and Clinical Excellence; 2010.

62. Le Page PA, Velu PP, Penman ID, Couper GW, Paterson-Brown S, Lamb PJ. Surgical and endoscopic management of high grade dysplasia and early oesophageal adenocarcinoma. Surgeon. Epub March 2, 2015 . 
63. Lam YH, Bright T, Leong M, Thompson SK, Mayne G, Watson DI. Oesophagectomy is a safe option for early adenocarcinoma arising from Barrett's oesophagus. ANZ J Surg. Epub February 23, 2015.

64. Wu J, Pan YM, Wang TT, Gao DJ, Hu B. Endotherapy versus surgery for early neoplasia in Barrett's esophagus: a meta-analysis. Gastrointest Endosc. 2014;79(2):233-241. e2.

65. Ertan A, Zaheer I, Correa AM, Thosani N, Blackmon SH. Photodynamic therapy vs radiofrequency ablation for Barrett's dysplasia: efficacy, safety and cost-comparison. World J Gastroenterol. 2013;19(41) $7106-7113$.

66. van Vilsteren FG, Pouw RE, Seewald S, et al. Stepwise radical endoscopic resection versus radiofrequency ablation for Barrett's oesophagus with high-grade dysplasia or early cancer: a multicentre randomised trial. Gut. 2011;60(6):765-773.

67. Zemlyak AY, Pacicco T, Mahmud EM, et al. Radiofrequency ablation offers a reliable surgical modality for the treatment of Barrett's esophagus with a minimal learning curve. Am Surg. 2012;78(7):774-778.

68. Shaheen NJ, Sharma P, Overholt BF, et al. Radiofrequency ablation in Barrett's esophagus with dysplasia. N Engl J Med. 2009;360(22): 2277-2288.

69. Ganz RA, Overholt BF, Sharma VK, et al. Circumferential ablation of Barrett's esophagus that contains high-grade dysplasia: a US Multicenter Registry. Gastrointest Endosc. 2008;68(1):35-40.

70. Vaccaro BJ, Gonzalez S, Poneros JM, et al. Detection of intestinal metaplasia after successful eradication of Barrett's Esophagus with radiofrequency ablation. Dig Dis Sci. 2011;56(7):1996-2000.

71. Pouw RE, Wirths K, Eisendrath P, et al. Efficacy of radiofrequency ablation combined with endoscopic resection for barrett's esophagus with early neoplasia. Clin Gastroenterol Hepatol. 2010;8(1):23-29.

72. Vassiliou MC, von Renteln D, Wiener DC, Gordon SR, Rothstein RI Treatment of ultralong-segment Barrett's using focal and balloon-based radiofrequency ablation. Surg Endosc. 2010;24(4):786-791.

73. Lyday WD, Corbett FS, Kuperman DA, et al. Radiofrequency ablation of Barrett's esophagus: outcomes of 429 patients from a multicenter community practice registry. Endoscopy. 2010;42(4):272-278.

74. Phoa KN, van Vilsteren FG, Weusten BL, et al. Radiofrequency ablation vs endoscopic surveillance for patients with Barrett esophagus and low-grade dysplasia: a randomized clinical trial. JAMA. 2014;311(12): 1209-1217.

75. Perry KA, Walker JP, Salazar M, Suzo A, Hazey JW, Melvin WS. Endoscopic management of high-grade dysplasia and intramucosal carcinoma: experience in a large academic medical center. Surg Endosc. 2014;28(3):777-782.

76. Fleischer DE, Overholt BF, Sharma VK, et al. Endoscopic radiofrequency ablation for Barrett's esophagus: 5-year outcomes from a prospective multicenter trial. Endoscopy. 2010;42(10):781-789.

77. Gondrie JJ, Pouw RE, Sondermeijer CM, et al. Effective treatment of early Barrett's neoplasia with stepwise circumferential and focal ablation using the HALO system. Endoscopy. 2008;40(5):370-379.

78. Dunbar KB, Spechler SJ. Controversies in Barrett esophagus. Mayo Clin Proc. 2014;89(7):973-984.

79. Gupta M, Iyer PG, Lutzke L, et al. Recurrence of esophageal intestinal metaplasia after endoscopic mucosal resection and radiofrequency ablation of Barrett's esophagus: results from a US Multicenter Consortium. Gastroenterology. 2013;145(1):79-86. e1.
80. Shaheen NJ, Overholt BF, Sampliner RE, et al. Durability of radiofrequency ablation in Barrett's esophagus with dysplasia. Gastroenterology. 2011;141(2):460-468.

81. Dulai PS, Pohl H, Levenick JM, Gordon SR, MacKenzie TA, Rothstein RI. Radiofrequency ablation for long- and ultralong-segment Barrett's esophagus: a comparative long-term follow-up study. Gastrointest Endosc. 2013;77(4):534-541.

82. Curvers WL, ten Kate FJ, Krishnadath KK, et al. Low-grade dysplasia in Barrett's esophagus: overdiagnosed and underestimated. Am J Gastroenterol. 2010;105(7):1523-1530.

83. Duits LC, Phoa KN, Curvers WL, et al. Barrett's oesophagus patients with low-grade dysplasia can be accurately risk-stratified after histological review by an expert pathology panel. Gut. 2015;64(5): 700-706.

84. Kaneshiro DK, Post JC, Rybicki L, Rice TW, Goldblum JR. Clinical significance of the duplicated muscularis mucosae in Barrett esophagusrelated superficial adenocarcinoma. Am J Surg Pathol. 2011;35(5): 697-700.

85. Nentwich MF, von Loga K, Reeh M, et al. Depth of submucosal tumor infiltration and its relevance in lymphatic metastasis formation for $\mathrm{T} 1 \mathrm{~b}$ squamous cell and adenocarcinomas of the esophagus. J Gastrointest Surg. 2014;18(2):242-249; discussion 249.

86. Bulsiewicz WJ, Kim HP, Dellon ES, et al. Safety and efficacy of endoscopic mucosal therapy with radiofrequency ablation for patients with neoplastic Barrett's esophagus. Clin Gastroenterol Hepatol. 2013;11(6): 636-642.

87. Davila ML, Hofstetter WL. Endoscopic management of Barrett's esophagus with high-grade dysplasia and early-stage esophageal adenocarcinoma. Thorac Surg Clin. 2013;23(4):479-489.

88. Chabrun E, Marty M, Zerbib F. Development of esophageal adenocarcinoma on buried glands following radiofrequency ablation for Barrett's esophagus. Endoscopy. 2012;(44 Suppl 2):E392. UCTN.

89. Titi M, Overhiser A, Ulusarac O, et al. Development of subsquamous high-grade dysplasia and adenocarcinoma after successful radiofrequency ablation of Barrett's esophagus. Gastroenterology. 2012;143(3): 564-566. e1.

90. Dunkin BJ, Martinez J, Bejarano PA, et al. Thin-layer ablation of human esophageal epithelium using a bipolar radiofrequency balloon device. Surg Endosc. 2006;20(1):125-130.

91. Hage M, Siersema PD, Vissers KJ, et al. Genomic analysis of Barrett's esophagus after ablative therapy: persistence of genetic alterations at tumor suppressor loci. Int J Cancer. 2006;118(1):155-160.

92. Paulson TG, Xu L, Sanchez C, et al. Neosquamous epithelium does not typically arise from Barrett's epithelium. Clin Cancer Res. 2006;12(6) 1701-1706.

93. Lopes CV, Pereira-Lima J, Hartmann AA. p53 immunohistochemical expression in Barrett's esophagus before and after endoscopic ablation by argon plasma coagulation. Scand J Gastroenterol. 2005;40(3): 259-263.

94. Pouw RE, Gondrie JJ, Rygiel AM, et al. Properties of the neosquamous epithelium after radiofrequency ablation of Barrett's esophagus containing neoplasia. Am J Gastroenterol. 2009;104(6):1366-1373.
Gastrointestinal Cancer: Targets and Therapy

\section{Publish your work in this journal}

Gastrointestinal Cancer: Targets and Therapy is an international, peer-reviewed, open access journal focusing on gastro-intestinal cancer research, identification of therapeutic targets and the optimal use of preventative and integrated treatment interventions to achieve improved outcomes, enhanced survival and quality of life for the

\section{Dovepress}

cancer patient. The manuscript management system is completely online and includes a very quick and fair peer-review system. Visit http://www.dovepress.com/testimonials.php to read real quotes from published authors. 